\title{
PHONOCARDIOGRAPHIC FEATURES OF THE SYSTOLIC MURMUR IN PULMONARY ARTERY STENOSIS
}

\author{
BY \\ GEORGE BOUSVAROS* AND WILFRED PALMER $\dagger$ \\ From the Joint Cardiorespiratory Service of the Royal Victoria Hospital and the Montreal Children's Hospital, \\ McGill University, Montreal, Quebec, Canada \\ Received July 29, 1964
}

The entity of pulmonary artery stenosis, alone or in association with other congenital cardiac defects, has been described in detail in recent years (Gunning, 1957; Gyllenswärd et al., 1957; Smith, 1958; Shafter and Bliss, 1959; Grosse-Brockhoff, 1961; Löhr, Loogen, and Vieten, 1961; Arvidsson et al., 1961; D’Cruz et al., 1964; Delaney and Nadas, 1964; Baum et al., 1964). From these reports it appears that the clinical recognition of the anomaly is difficult except in the presence of a continuous murmur radiating widely to one or both axillae and the back. In the majority of the reported cases, however, a basal systolic murmur was observed; this, too, often showed a wide lateral propagation suggestive of the diagnosis.

In a case of pulmonary artery stenosis recently observed in this department it was noted that the basal systolic murmur had characteristic timing and configuration. We think that these features are present in most, if not all, cases of pulmonary artery stenosis with a systolic murmur, and their recognition should provide additional help in the clinical diagnosis of the lesion.

\section{HÆMOdYNAMIC FEATURES}

The 26-year-old woman presented with clinical, electrocardiographic, and radiological features suggestive of atrial septal defect. Right heart catheterization substantiated the clinical impression by demonstrating left-to-right shunt at atrial level with pulmonary to systemic flow ratio of 3 to 1 . In addition a systolic gradient of $12 \mathrm{~mm}$. $\mathrm{Hg}$ was found between the right and main pulmonary artery (Fig. $1 \mathrm{~A}$ and B). By rapid withdrawal of the catheter (Fig. 1C) a gradient across the pulmonary valve was simulated, presumably as a result of failure to record beats from the main pulmonary artery proximal to the stenosis. Cine-angiocardiography demonstrated narrowing at the origin of the right pulmonary artery (Fig. 2). This served to confirm the diagnosis which might otherwise be questioned in view of the occasional occurrence of functional gradients in branches of the pulmonary artery with high pulmonary flow (D’Cruz et al., 1964; Delaney and Nadas, 1964).

\section{Auscultatory and Phonocardiographic Signs}

These consisted of a grade $2-3 / 6$ ejection systolic murmur at the pulmonary area, equally well heard at the aortic area, with a widely split, fixed, second sound and a tricuspid mid-diastolic flow murmur. However, in contrast to the usual case of atrial septal defect in which the murmur has a

* Supported by the John A. Hartford Foundation.

$\uparrow$ Research Associate of the Heart Foundation of Canada. 

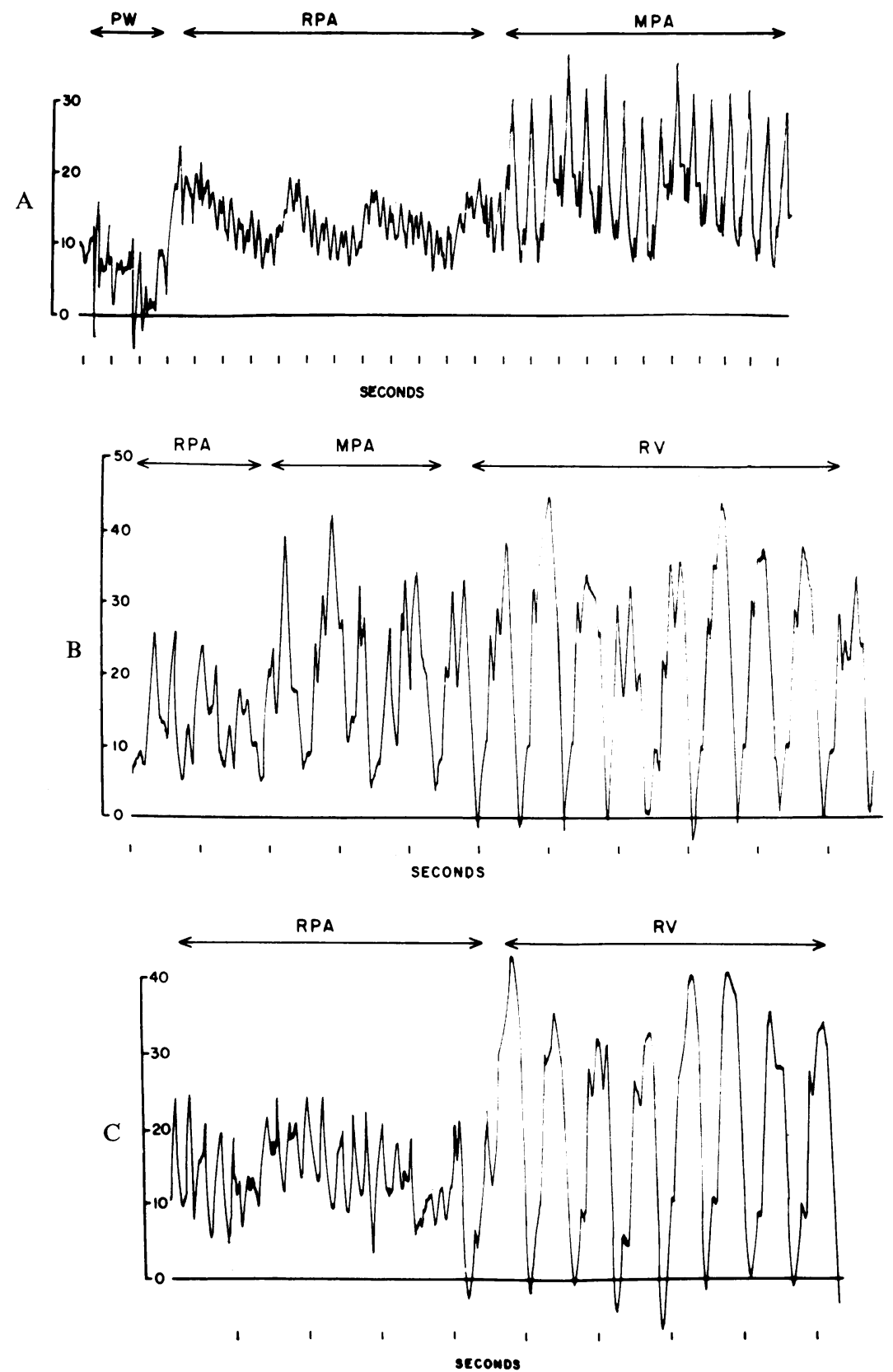

FIG. 1.-Continuous withdrawal pressure tracings (A) from the right pulmonary wedge into the right and then into the main pulmonary artery, and (B) from the right into the main pulmonary artery and the right ventricle. The gradient between the right and main pulmonary artery is well shown. There is no gradient across the pulmonary valve. (C) During rapid withdrawal of the catheter the gradient is spuriously shown to be at the valve. (The tracings have been retouched.)

crescendo in early to mid systole and terminates before A2 (Leatham and Gray, 1956), the systolic murmur in this case started 0.04 to $0.06 \mathrm{sec}$. after the tricuspid component of the first sound, reached a crescendo in mid to late systole, and terminated beyond A2 partially enveloping P2 (Fig. 3). These 


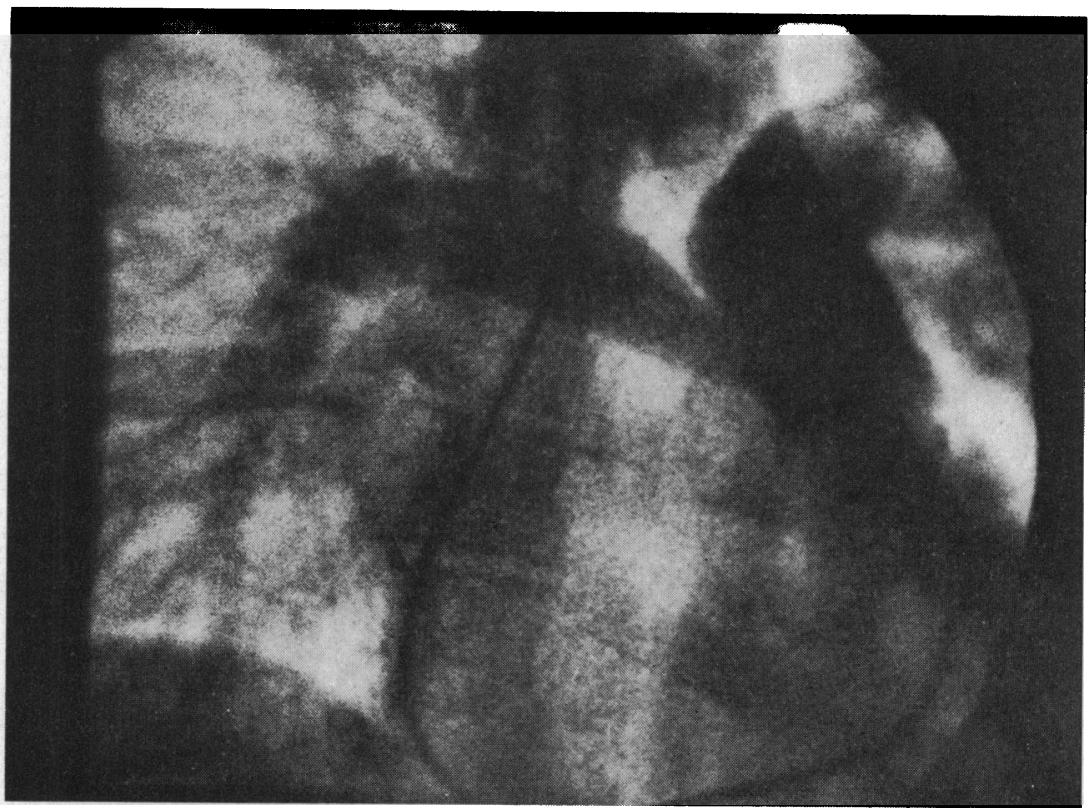

Fig. 2.-Cine-angiocardiogram demonstrates stenosis at the origin of the right pulmonary artery.

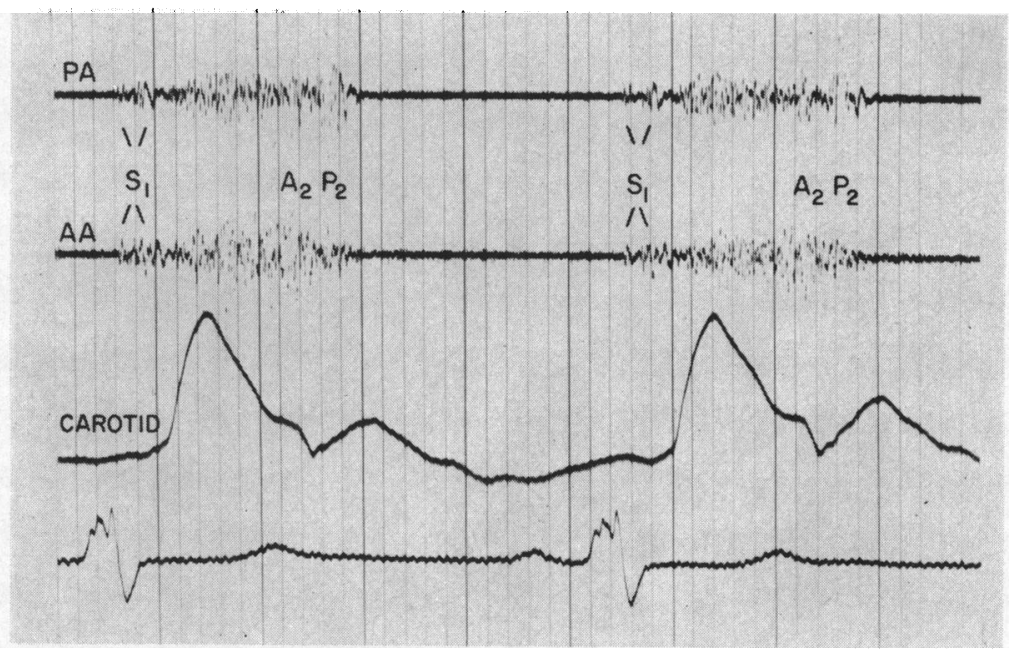

FIG. 3.-At the aortic area (AA) the systolic murmur has a delayed onset, crescendo, and termination and envelops A2 and P2. At the pulmonary area (PA) the murmur has an earlier crescendo than in the aortic area, but still late compared to uncomplicated atrial septal defect.

features were more pronounced over the second right and less so at the second left interspace where the murmur had a slightly earlier crescendo and obscured the two components of the second sound to a lesser degree. On careful auscultation the murmur could be faintly detected at the right axilla.

\section{DisCussion}

It seems likely that the delayed systolic murmur recorded in the present case over the right second interspace was produced by the stenosed right pulmonary artery while the widely split 
second sound and the flow murmur were due to the associated interatrial communication. The pulmonary ejection murmur of the atrial septal defect predominated at the second left interspace, as evidenced by the earlier crescendo at this area (Fig. 3).

A delay in the onset, crescendo, and termination of the systolic murmur of pulmonary artery stenosis, with obscuring of the two components of the second sound, has not been mentioned in previous articles except in the legend of an illustration in Nadas's Pediatric Cardiology (1963). These features are also apparent in phonocardiograms of other publications (Gyllenswärd et al., 1957; Grosse-Brockhoff, 1961; Löhr et al., 1961). The presence of these features may be predicted by the location of the narrowing distal to the pulmonary valve, as demonstrated with the delayed systolic murmur in coarctation of the aorta (Spencer, Johnston, and Meredith, 1958; Cassels and Tatooles, 1964). Thus it is reasonable to suggest that a delayed timing and configuration should be exhibited by the basal systolic murmur of most, if not all, cases of pulmonary artery stenosis. Coarctation of the aorta should be considered in the differential diagnosis but its recognition is not difficult. A similar murmur in severe aortic or pulmonary valve stenosis should be differentiated from the other clinical signs and in particular from the second sound which in severe aortic stenosis may be paradoxically split (Gray, 1956), while in severe pulmonary stenosis it is widely split with faint P2 (Leatham and Weitzman, 1957). Mild aortic or pulmonary stenosis and atrial septal defect may also be distinguished by the early crescendo of the systolic murmur. In cases of pulmonary artery stenosis associated with other congenital heart lesions it would still be unusual for the murmur of the additional anomaly to obscure the morphology of the systolic murmur of the branch stenosis. The described features should, therefore, prove of considerable help in drawing the attention of the clinician to the possibility of pulmonary artery stenosis.

The gradient across the pulmonary valve simulated by rapid withdrawal of the catheter from the post-stenotic segment direct into the right ventricle (Fig. 1C) illustrates an additional way in which a so-called "functional" pulmonary valve gradient may be produced in atrial septal defect. Before assuming the functional nature of such a gradient, it is important to exclude pulmonary artery stenosis by catheterization of both branches of the pulmonary artery and by angiocardiography.

\section{SUMMARY AND CONCLUSION}

In a patient with right pulmonary artery stenosis and atrial septal defect, the basal systolic murmur of the branch stenosis had a delayed onset, crescendo, and termination, and obscured the two components of the second sound. It is concluded that this type of systolic murmur is very suggestive of peripheral pulmonary artery stenosis.

\section{REFERENCES}

Arvidsson, H., Carlsson, E., Hartmann, A., Jr., Tsifutis, A., and Crawford, C. (1961). Supravalvular stenoses of the pulmonary arteries: Report of eleven cases. Acta radiol. (Stockh.), 56, 466.

Baum, D., Khoury, G. H., Ongley, P. A., Swan, H. J. C., and Kincaid, O. W. (1964). Congenital stenosis of the pulmonary artery branches. Circulation, 29, 680.

Cassels, D. E., and Tatooles, C. J. (1964). Auscultatory features of coarctation of the aorta. In Theory and Practice of Auscultation, ed. B. L. Segal, p. 272. F. A. Davies Philadelphia.

D'Cruz, I. A., Agustsson, M. H., Bicoff, J. P., Weinberg, M., Jr., and Arcilla, R. A. (1964). Stenotic lesions of the pulmonary arteries. Clinical and hemodynamic findings in 84 cases. Amer. J. Cardiol., $13,441$.

Delaney, T. B., and Nadas, A. S. (1964). Peripheral pulmonic stenosis. Amer. J. Cardiol., $13,451$.

Gray, I. R. (1956). Paradoxical splitting of the second heart sound. Brit. Heart J., 18, 21.

Grosse-Brockhoff, F. (1961). Periphere Pulmonalstenose. Cardiologia (Basel), 38, 142.

Gunning, A. J. (1957). An unusual cause of a continuous murmur simulating persistent ductus arteriosus and associated with other congenital cardiac defects. Thorax, 12, 34.

Gyllenswärd, $\AA$., Lodin, H., Lundberg, $\AA$. , and Möller, T. (1957). Congenital, multiple peripheral stenoses of the pulmonary artery. Pediatrics, 19, 399.

Leatham, A., and Gray, I. (1956). Auscultatory and phonocardiographic signs of atrial septal defect. Brit. Heart J., 18, 193.

- and Weitzman, D. (1957). Auscultatory and phonocardiographic signs of pulmonary stenosis. Brit. Heart J., 19, 303. 
Löhr, H., Loogen, F., and Vieten, H. (1961). Die periphere Pulmonalstenose. Fortschr. Röntgenstr., 94, 285.

Nadas, A. S. (1963). Pediatric Cardiology, 2nd ed., p. 670. Saunders, Philadelphia and London.

Shafter, H. A., and Bliss, H. A. (1959). Pulmonary artery stenosis. Amer. J. Med., 26, 517.

Smith, W. G. (1958). Pulmonary hypertension and a continuous murmur due to multiple peripheral stenoses of the pulmonary arteries. Thorax, 13, 194.

Spencer, M. P., Johnston, F. R., and Meredith, J. H. (1958). The origin and interpretation of murmurs in coarctation of the aorta. Amer. Heart J., 56, 722. 